\title{
Development of creep-resistant magnesium casting alloys for high temperature automotive applications
}

\author{
L. Han, H. Hu \& D. O. Northwood \\ Department of Mechanical, Automotive \& Materials Engineering, \\ University of Windsor, Canada
}

\begin{abstract}
The low specific gravity of magnesium has made Mg-alloys attractive for automotive and aerospace applications. Conventional $\mathrm{Mg}$ casting alloys have been based on the Mg-Al system with additions of $\mathrm{Zn}, \mathrm{Mn}$ or Si, e.g. AZ91 alloy (Mg-9.0Al-1.0Zn, wt.\%). Such alloys, which have good castability, mechanical properties and corrosion resistance, are widely used in the automotive industry. However, due to the rapid degradation of the mechanical properties at elevated temperatures, especially the creep resistance, application of these alloys has been limited to specific components that operate at temperatures below $150{ }^{\circ} \mathrm{C}$. New creep-resistant $\mathrm{Mg}$ casting alloys are required for application as transmission cases (temperatures up to $\sim 175{ }^{\circ} \mathrm{C}$ ), engine blocks $\left(\sim 250{ }^{\circ} \mathrm{C}\right)$ and pistons $\left(\sim 300{ }^{\circ} \mathrm{C}\right)$. The development of such high performance creep-resistant alloys requires the development of microstructures in the cast alloy that both prevent grain boundary sliding and restrict the motion of lattice dislocations within the primary $\alpha-\mathrm{Mg}$ grains. The development of Mg-Al-Ca casting alloys is described where Ca-containing eutectic phases are precipitated along the grain boundaries and where dislocation motion within the grains is restricted due to solid solution hardening and the presence of dispersed nanoscale eutectic phases

Keywords: magnesium alloy, calcium addition, creep resistance, solid solution hardening, dispersion hardening.
\end{abstract}




\section{Introduction}

Magnesium alloys are widely used in the automotive and aerospace industries because of their specific weight advantages over aluminum alloys, steel and other materials [1]. A large number of magnesium alloys have been developed based on the good castability of the magnesium-aluminum system with additions of $\mathrm{Zn}, \mathrm{Mn}$, and in some cases Si. However, conventional Mg-Al and Mg-Al-Zn type alloys have certain limitations in industrial applications. Due to a rapid degradation of their mechanical properties at elevated temperatures, especially the creep resistance, they are not suitable for specific components that operate at temperatures over $150^{\circ} \mathrm{C}[1-3]$.

Due to its low-cost and density, the addition of $\mathrm{Ca}$ to $\mathrm{Mg}-\mathrm{Al}$ alloys has been designated for further development aimed at improving both room-temperature and elevated-temperature mechanical properties. In these alloys, Ca-containing eutectic phases gradually replace the $\beta-\mathrm{Mg}_{17} \mathrm{Al}_{12}$ phases, and enhanced mechanical properties are obtained by the refinement of the microstructure with an increase in $\mathrm{Ca}$ content. However, a detailed study of the microstructural dependence on the level of $\mathrm{Ca}$ addition had not been reported. The eutectic compounds formed in $\mathrm{Mg}-\mathrm{Al}-\mathrm{Ca}$ alloys are variously reported to be $\mathrm{Al}_{2} \mathrm{Ca}$ [4], $\mathrm{Mg}_{2} \mathrm{Ca}$ [5], $(\mathrm{Al}, \mathrm{Mg})_{2} \mathrm{Ca}$ [6-9] and mixtures of these three phases [10] because of the similarity of their crystal structures.

In the present study, AM50 and Mg-5.0 wt.\% Al alloys containing 1.0 to 2.0 wt.\% Ca were produced using a permanent mold casting process. The resulting microstructures were characterized by SEM and TEM. Localized mechanical behaviors including microhardness and nano-indentation creep resistance were determined.

\section{Experimental}

The AM50 (Mg-5.0Al-0.3Mn, wt.\%) and the Mg-Al-Ca (Mg-5.0Al-1.0Ca and $\mathrm{Mg}-5.0 \mathrm{Al}-2.0 \mathrm{Ca}$, wt.\%) alloys were produced by permanent mold casting (PM).

To reveal the microstructural characteristics of the alloys, samples were polished with suspensions of $1 \mu \mathrm{m}$ and $0.05 \mu \mathrm{m}$ alumina polishing powders, and then chemically etched in a Glycol etchant $\left(75 \mathrm{ml}\right.$ ethylene glycol, $1 \mathrm{ml} \mathrm{HNO}_{3}$, $25 \mathrm{ml} \mathrm{H}_{2} \mathrm{O}$ ). The morphological and microchemical characterizations of polished and etched surfaces were characterized with a JEOL JSM-5800LV scanning electron microscope (SEM). Samples for TEM were ground with Carbimet abrasive papers to a thickness of $\sim 20 \mu \mathrm{m}$, then further thinned by ion beam milling with an incidence angle of $3 \sim 5^{\circ}$. The thin foils were observed using a JEOL 2010 transmission electron microscope (TEM) instrument equipped with an energy dispersive X-ray spectrometer (EDS) at an operating voltage of 200 $\mathrm{keV}$.

A Buehler microhardness tester was used to measure the Vickers microhardness with a load of $200 \mathrm{~g}$ to investigate the effects of the $\mathrm{Ca}$ content on the hardness of the as-cast $\mathrm{Mg}-\mathrm{Al}$ and $\mathrm{Mg}-\mathrm{Al}-\mathrm{Ca}$ alloys. The nano-indentation creep tests were performed on a Hysitron $\mathrm{Ubi}^{\circledR} 1$ nanomechanical test instrument 
with a Berkovich indenter at room temperature. Before the microhardness and indentation creep tests, the specimens were subjected to mechanical polishing using a $0.05 \mu \mathrm{m}$ alumina suspension.

\section{Results and discussion}

To investigate the effect of Ca content on microstructure of the PM Mg-Al-Ca alloys, two different levels of $\mathrm{Ca}$ addition (1.0 and $2.0 \mathrm{wt} . \%$ ) were introduced to the AM50 base alloy. SEM micrographs showing the development of the microstructure of the $\mathrm{Mg}-\mathrm{Al}$ and $\mathrm{Mg}$-Al-Ca alloys are presented in Fig. 1.

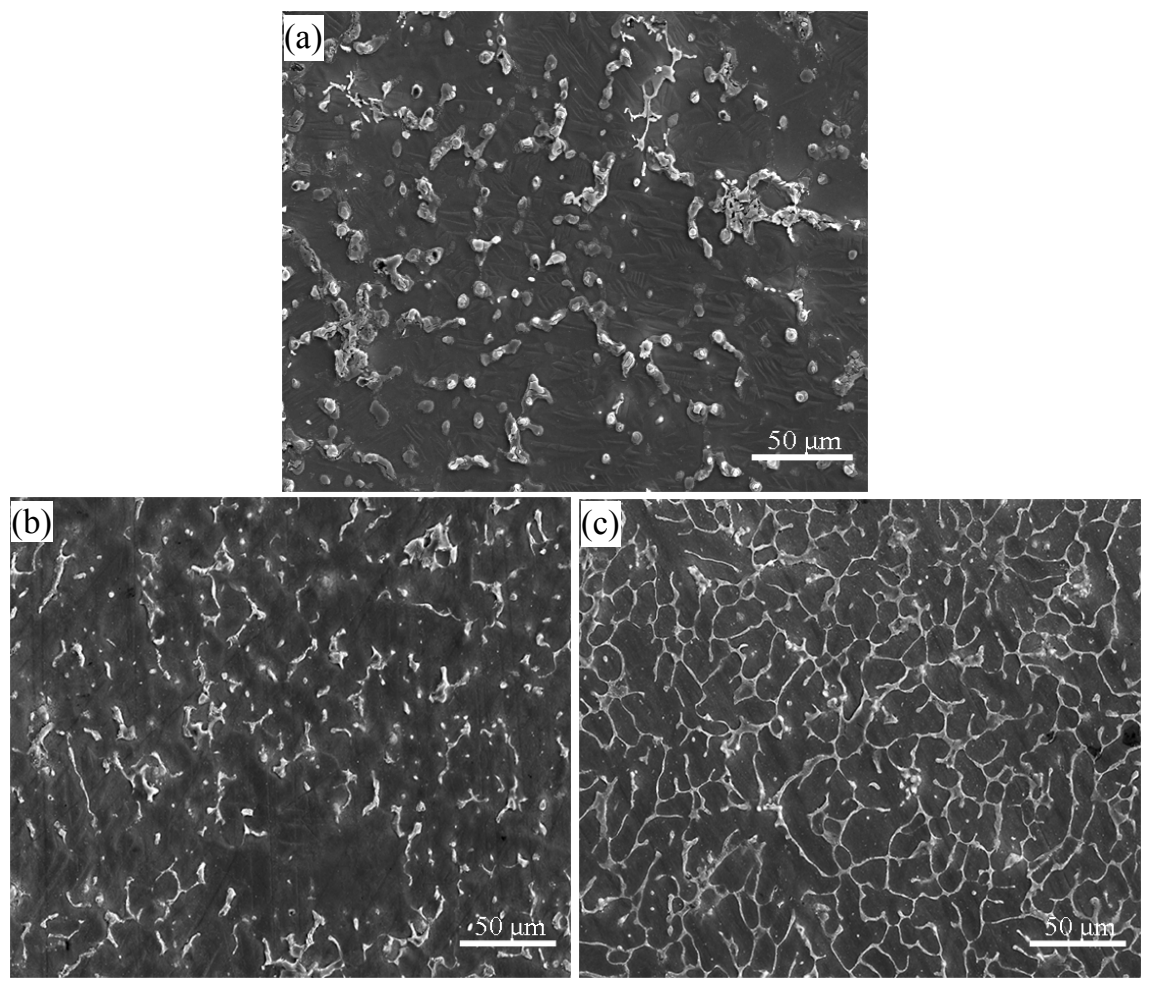

Figure 1: $\quad$ SEM micrographs of the microstructural evolution of the PM Mg-Al-Ca alloys with different Ca contents: (a) 0.0, (b) 1.0 and (c) 2.0 (wt. \%).

The marked grain refining effect of a high Ca addition (Fig.1 (c)) is clearly evident compared to the specimen without a $\mathrm{Ca}$ addition (Fig.1 (a)) under the same casting conditions. The completely divorced, discontinuous eutectic phases have gradually been replaced by a continuous network of eutectic phases with increasing $\mathrm{Ca}$ content. The grain refining effect of $\mathrm{Ca}$ was further confirmed by 
quantitative image analysis to measure the secondary dendrite arm spacing (SDAS) and the volume fraction of the secondary eutectic phase. The results show that, as the Ca content increases from 0.0 to $2.0 \mathrm{wt} . \%$, the measured SDAS values decrease from $39.1 \pm 6.4 \mu \mathrm{m}$ to $9.8 \pm 3.1 \mu \mathrm{m}$, while the measured volume fractions of the eutectic phases increase from $5.6 \pm 3.1 \%$ to $21.4 \pm 4.2 \%$.
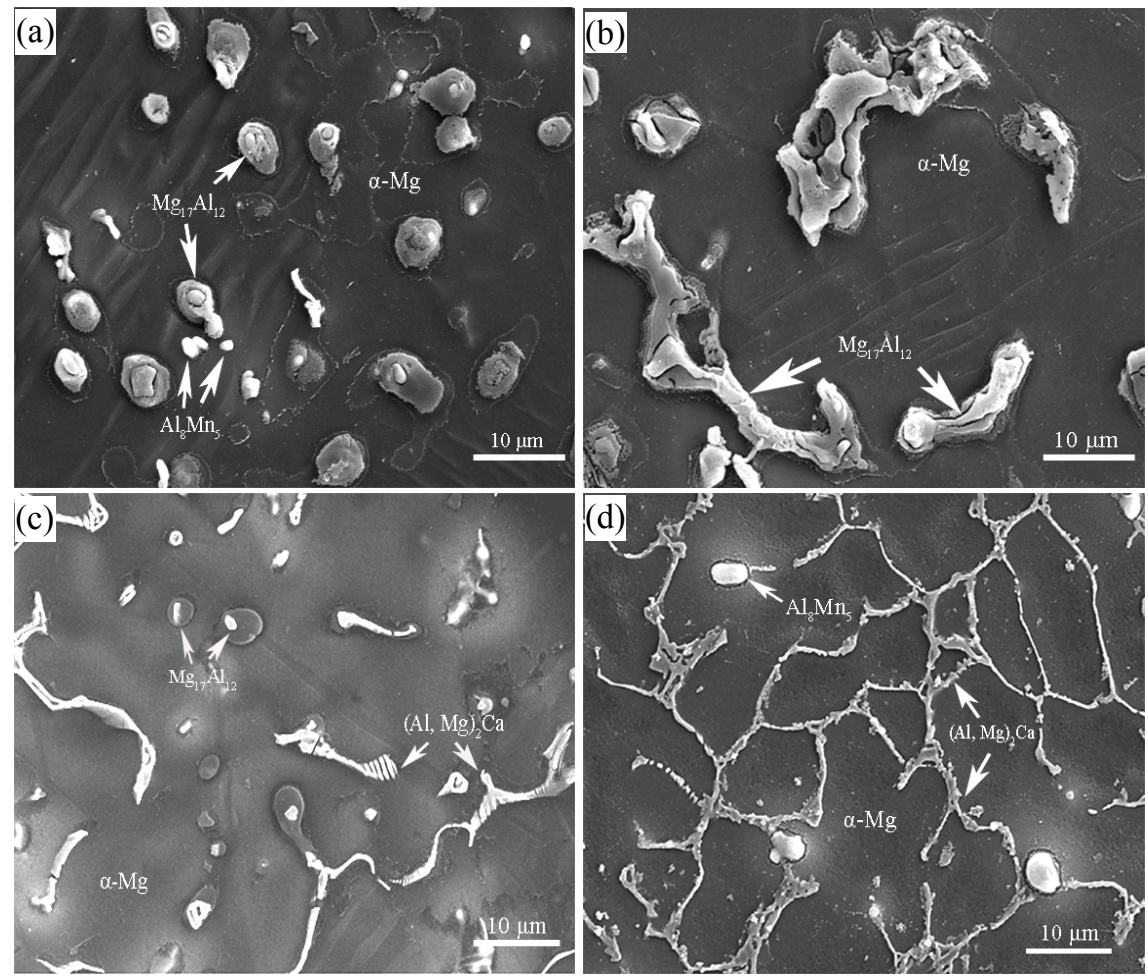

Figure 2: $\quad$ SEM micrographs of the PM AM50 alloy in: (a) skin region, and (b) central region, and the PM AC51 alloy in: (c) central region and the PM AC52 alloy in: (d) central region.

Fig. 2 shows the microstructural evolution of the Mg-Al alloys with different calcium contents. Figs. 2 (a) and (b) show the typical microstructures in the skin and center regions of the PM AM50 alloy. It can be seen that the microstructures consist of the primary $\alpha-\mathrm{Mg}, \beta-\mathrm{Mg}_{17} \mathrm{Al}_{12}$ and $\mathrm{Al}_{8} \mathrm{Mn}_{5}$ phases. The $\beta-\mathrm{Mg}_{17} \mathrm{Al}_{12}$, with a less bright contrast, is often surrounded by the eutectic $\alpha-\mathrm{Mg}$, while the bright white spots visible on the SEM image are $\mathrm{Al}_{8} \mathrm{Mn}_{5}$ precipitates. The morphology of the eutectic phases, including $\beta-\mathrm{Mg}_{17} \mathrm{Al}_{12}$ and eutectic $\alpha-\mathrm{Mg}$ in the skin and the central regions, was obviously different, as is shown in Figs. 2(a) and (b). A large number of discrete, round eutectic islands were observed in the skin of the casting. $\mathrm{A} \beta-\mathrm{Mg}_{17} \mathrm{Al}_{12}$ particle is in the middle of the island, and is surrounded by the eutectic $\alpha-\mathrm{Mg}$. However, some long eutectic islands, as well 
as the round eutectic islands, were found in the middle of the casting. The $\beta$ $\mathrm{Mg}_{17} \mathrm{Al}_{12}$ particles in these long islands are noticeably coarser than those in the skin region. Additionally, the $\beta-\mathrm{Mg}_{17} \mathrm{Al}_{12}$ phases were discontinuously distributed in both regions of the casting.

With the addition of $\mathrm{Ca}$ to the $\mathrm{Mg}-\mathrm{Al}$ alloy, typical dendritic microstructures were observed in the PM AC51 and AC52 alloys, as shown in Figs. 2 (c) and (d), respectively. Compared to the PM AM50 alloy, there were larger numbers of the Ca-containing interdendritic phases formed along the grain boundaries by the eutectic reaction in the PM AC51 and AC52 alloys because the Ca-containing phases suppress the formation of the $\beta-\mathrm{Mg}_{17} \mathrm{Al}_{12}$ phase. However, due to the relatively lower amount of $\mathrm{Ca}(1 \%)$, some $\beta-\mathrm{Mg}_{17} \mathrm{Al}_{12}$ phase were still formed in the matrix of the PM AC51 alloy. Also, it is difficult to distinguish the Cacontaining phase from the $\beta-\mathrm{Mg}_{17} \mathrm{Al}_{12}$ phase in SEM micrographs due to their similar contrast. When $\mathrm{Ca}$ content reaches $2.0 \mathrm{wt} . \%$, the main eutectic phases are Ca-containing phases in the AC52 alloy.

Another important finding is that the Al-rich eutectic $\alpha-\mathrm{Mg}$ phase disappears in the PM AC52 alloy, which is usually present in die cast Mg-Al-Mn alloys [1114]. Also, the difference in the SDAS between the edge and the center of the castings is significantly reduced through the addition of $\mathrm{Ca}$. For example, the average SDAS measured in the edge and the center of the PM AC52 alloy is 7.8 $\pm 2.1 \mu \mathrm{m}$ and $9.8 \pm 3.1 \mu \mathrm{m}$, respectively, as shown in Fig. 3.
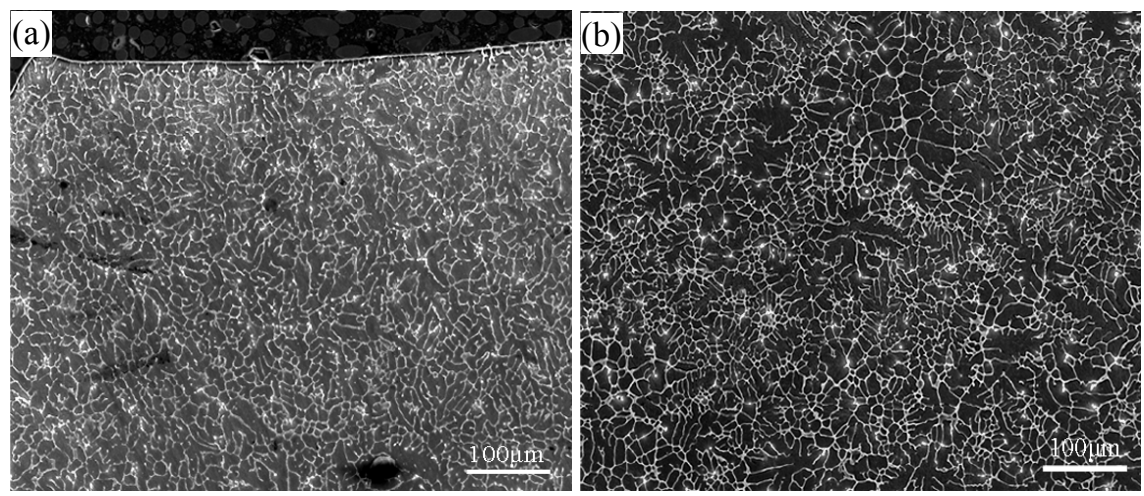

Figure 3: $\quad$ SEM micrographs of precipitation phases in: (a) skin region and (b) central region of the PM AC52 alloy.

The $\beta-\mathrm{Mg}_{17} \mathrm{Al}_{12}$ precipitates in the as-cast $\mathrm{Mg}$-Al alloys have a typical lamellar structure with an irregular shape [15]. The Ca-containing eutectic phases along the grain boundaries have a 'rib' shape with lamellae structures that are arranged in alternating layers of the Ca-containing phase and the eutectic $\mathrm{Mg}$ phase, and the selected area diffraction pattern further confirms that the $\mathrm{Ca}$ containing phase is the $(\mathrm{Al}, \mathrm{Mg})_{2} \mathrm{Ca}$ phase which has a hexagonal structure [15]. Similar results have been reported by Luo et al [8]. 
It was reported [16] that two endothermic peaks at low $\left(425\right.$ to $457{ }^{\circ} \mathrm{C}$ : dissolution of eutectic $\beta-\mathrm{Mg}_{17} \mathrm{Al}_{12}$ phase) and high $\left(530\right.$ to $565{ }^{\circ} \mathrm{C}$ : dissolution of $(\mathrm{Al}, \mathrm{Mg})_{2} \mathrm{Ca}$ eutectic phase) temperatures are present for the AC51 alloy, while there is only one high temperature peak (530 to $565^{\circ} \mathrm{C}$ ) for the AC52 alloy during DSC heating. Obviously, the $(\mathrm{Al}, \mathrm{Mg})_{2} \mathrm{Ca}$ phase has enhanced stability at higher temperatures (100 K higher than $\beta-\mathrm{Mg}_{17} \mathrm{Al}_{12}$ phase), contributing to an increased creep resistance, while also suppressing the formation of the $\beta$ $\mathrm{Mg}_{17} \mathrm{Al}_{12}$ phase with increasing Ca content.

SEM micrograph and elemental maps from the same region for the PM AC52 alloy [15] showed that the main alloying elements, $\mathrm{Al}$ and $\mathrm{Ca}$, were mainly distributed along the grain boundaries. The $\mathrm{Al}_{8} \mathrm{Mn}_{5}$ phase, in the form of bright particles, were more or less randomly distributed within the grains, or at the grain boundaries, throughout the matrix of these two alloys. Also, the EDS results showed that there were still some $\mathrm{Al}$ and $\mathrm{Ca}$ retained within the grains due to rapid solidification, which contributes to a solid solution strengthening effect.

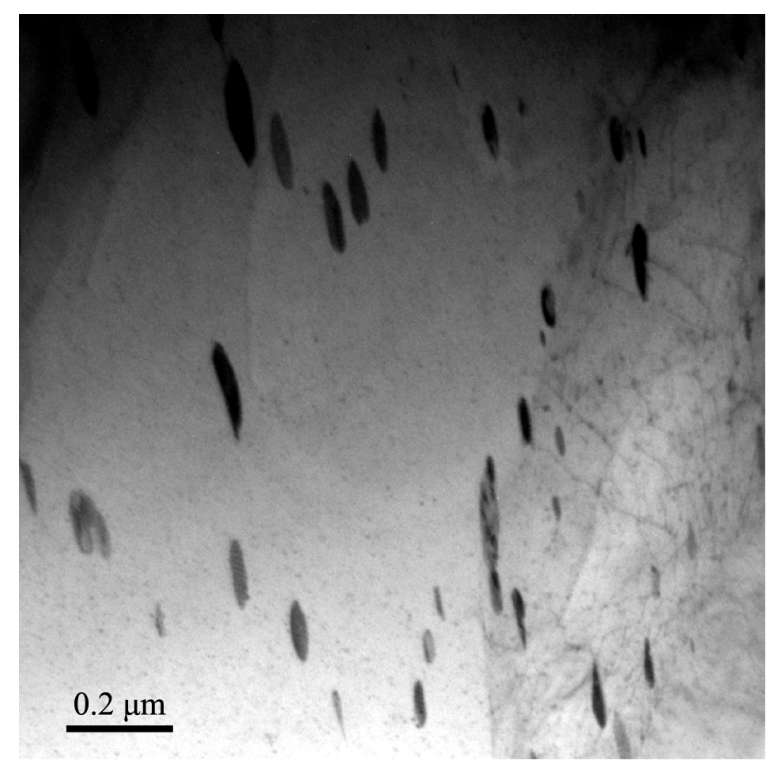

Figure 4: TEM micrograph of dispersed eutectic phases in the AC52 alloy.

It is worthwhile noting that, despite the fact that no dispersed precipitate were observed on the microscale in the primary $\alpha-\mathrm{Mg}$ grains of the AC52 alloy (Fig. 2 (d)), nanoscale Ca-containing precipitates in the primary phases were seen in the TEM bright field micrographs (Fig. 4). This observation suggests the formation of precipitates of the $(\mathrm{Al}, \mathrm{Mg})_{2} \mathrm{Ca}$ phase, resulting from a reaction taking place between $\mathrm{Al}$ in the AM50 alloy and the $\mathrm{Mg}_{2} \mathrm{Ca}$ intermetallic phase present in the 
master alloy during the alloy preparation even above the liquidus temperature of the cast alloy. The rapid cooling had a quenching effect on these nanoscale particles during the permanent mold casting process.

The average hardness values across the casting thickness and the difference in hardness between the skin and central regions for the three $\mathrm{PM} \mathrm{Mg-Al}$ and $\mathrm{Mg}-$ Al-Ca alloys are shown in Fig. 5. In all three alloys, the skin region was consistently harder than the central region. It was also found that the difference in hardness between the skin and central regions decreases with increasing $\mathrm{Ca}$ content in $\mathrm{Mg}-\mathrm{Al}$ alloy. Additionally, the average hardness across the casting thickness increases with increase in $\mathrm{Ca}$ content, reflecting the precipitation hardening and solid solution hardening effects of the $\mathrm{Ca}$ addition. Compared to the average hardness of the PM AM50 (54.6 $\left.\mathrm{kgf.mm}^{-2}\right)$, the average hardness of the PM AC52 alloy increased by $9.6 \mathrm{kgf.mm}{ }^{-2}$.

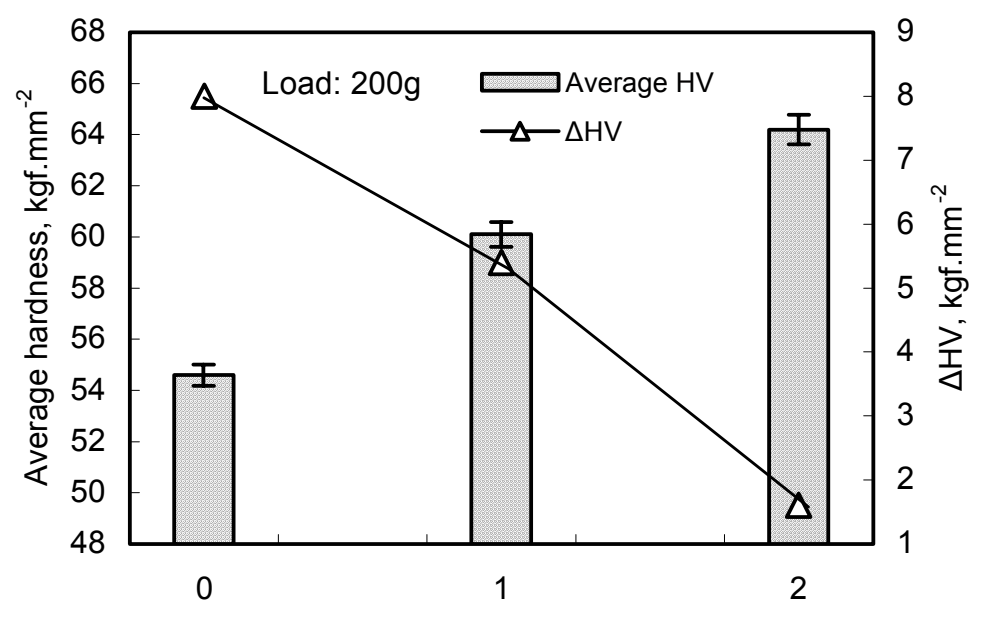

Ca content, wt.\%

Figure 5: Average hardness values across the casting thickness and the hardness difference between the skin and central regions for the three PM Mg-Al and Mg-Al-Ca alloys.

Fig. 6 shows the nanoindentation creep curves for the PM AM50, AC51 and AC52 alloys cast under the same solidification condition at an applied load of 5 $\mathrm{mN}$ at room temperature. The indentation penetration depth rapidly increases in a short time at the beginning of the indentation testing (primary stage) when a Berkovich indenter is pressed into the surface of the samples, and then the indenter slowly penetrates the samples by creeping until an apparent steady-state rate is finally reached (the secondary stage). It can be also seen in Fig. 6 that the PM AC52 alloy shows lower penetration depths than the PM AM50 and AC51 alloys at the same indentation time, which means that the PM AC52 alloy has better creep resistance than the PM AM50 and AC51 alloys. The indents of 
indentation creep tests were located within the primary $\alpha-\mathrm{Mg}$ grains. Hence, the dispersion hardening and solid solution hardening should be responsible for improved creep resistance. The enhanced creep resistance of the PM AC52 alloy indicates that there are more fine dispersed precipitates and alloying elements in the matrix of the PM AC52 alloy [17].

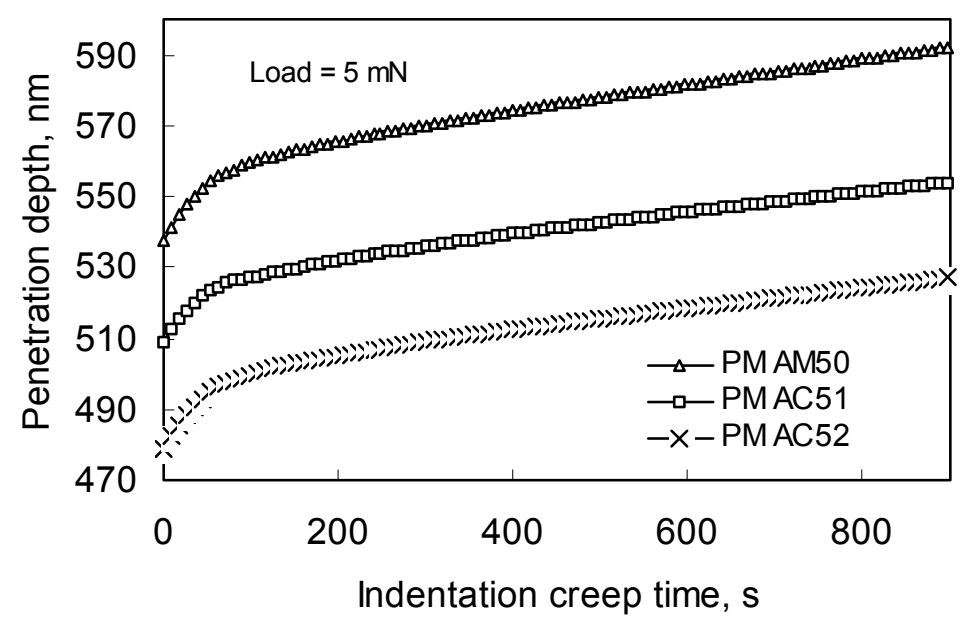

Figure 6: Indentation creep curves for PM AM50, AC51 and AC52 alloys at an applied load of $5 \mathrm{mN}$ at room temperature.

Improved creep resistance would also result from the improved thermal stability of the $(\mathrm{Mg}, \mathrm{Al})_{2} \mathrm{Ca}$ phase compared to the $\mathrm{Mg}_{17} \mathrm{Al}_{12}$ phase in the $\mathrm{Mg}-\mathrm{Al}$ alloy [9] and its resisting effect on grain boundary sliding when it is a coherent precipitate distributed at the grain boundaries $[8,18]$.

\section{Conclusions}

The addition of calcium to a $\mathrm{Mg}-\mathrm{Al}$ alloy produced the significant refinement of the microstructure. The coarse, discontinuous eutectic phases in the PM AM50 alloy were gradually replaced by fine $(\mathrm{Al}, \mathrm{Mg})_{2} \mathrm{Ca}$ eutectic phases with increasing Ca content. Quantitative image analysis further showed that, as the $\mathrm{Ca}$ content increased from 0.0 to $2.0 \mathrm{wt} . \%$, the measured SDAS values decreased from $39.1 \pm 6.4 \mu \mathrm{m}$ to $9.8 \pm 3.1 \mu \mathrm{m}$, while the measured volume fraction of the eutectic phases increased from $5.6 \pm 3.1 \%$ to $21.4 \pm 4.2 \%$. When the Ca content reached $2.0 \mathrm{wt} . \%$, the $\beta-\mathrm{Mg}_{17} \mathrm{Al}_{12}$ phase was completely replaced by the $(\mathrm{Al}$, $\mathrm{Mg})_{2} \mathrm{Ca}$ phase (AC52 alloy). As an endothermic peak $\left(530\right.$ to $565{ }^{\circ} \mathrm{C}$ ) during a $\mathrm{DSC}$ run, the $(\mathrm{Al}, \mathrm{Mg})_{2} \mathrm{Ca}$ phase show enhanced stability at higher temperatures than $\beta-\mathrm{Mg}_{17} \mathrm{Al}_{12}$ phase $\left(425\right.$ to $457{ }^{\circ} \mathrm{C}$ ), contributing to an increased creep resistance. The step-shaped $(\mathrm{Al}, \mathrm{Mg})_{2} \mathrm{Ca}$ phase present along the grain boundaries in the Ca-containing AC51 and AC52 alloys is capable of effectively 
blocking the movement of the dislocations and the sliding of the grain boundaries. The average hardness across the casting thickness increased with an increase in $\mathrm{Ca}$ content, reflecting the precipitation hardening and solid solution hardening effects of the $\mathrm{Ca}$ addition in the alloys. Compared to the average hardness of the PM AM50 (54.6 $\left.\mathrm{kgf.mm}^{-2}\right)$, the average hardness of the PM AC52 alloy increased by $9.6 \mathrm{kgf} . \mathrm{mm}^{-2}$. The PM AC52 alloy had better creep resistance than the PM AM50 and AC51 alloys, resulting from more fine dispersed precipitates and alloying elements in solution of the matrix of the PM AC52 alloy.

\section{Acknowledgements}

The authors would like to thank the Natural Sciences and Engineering Research Council of Canada (NSERC) for supporting this work. One author, Lihong Han, wishes to acknowledge the Government of Ontario and University of Windsor for financial support.

\section{References}

[1] Hu H., Yu A., Li N. \& Allison J. E., Potential magnesium alloys for high temperature die cast automotive applications: A review. Materials and Manufacturing Processes, 18(5), pp. 687-717, 2003.

[2] Yuan G., Wang Q. \& Ding W., High temperature deformation behavior of permanent casting AZ91 alloy with and without Sb addition. Journal of Materials Science, 37 (1), pp. 127-132, 2002.

[3] Moreno I. P., Nandy T. K., Jones J. W., Allison J. E. \& Pollock T. M., Microstructural stability and creep of rare-earth containing magnesium alloys. Scripta Materialia, 48(8), pp. 1029-1034, 2003.

[4] Hu H., Shang R. \& Li N., Effect of Ca addition on grain microstructure development of Mg alloy AM60. AFS Transactions, 111, pp. 1019-1029, 2003.

[5] Ozturk K., Zhong Y., Luo A. \& Liu Z., Creep resistant Mg-Al-Ca alloys: Computational thermodynamics and experimental investigation. JOM, 55(11), pp. 40-44, 2003.

[6] Luo A. \& Powell R., Tensile and compressive creep of magnesiumaluminum-calcium based alloys. Magnesium Technology 2001, TMS Annual Meeting, pp. 137-144, 2001.

[7] Suzuki A., Saddock N. D., Jones J. W. \& Pollock T. M., Structure and transition of eutectic $(\mathrm{Mg}, \mathrm{Al})_{2} \mathrm{Ca}$ Laves phase in a die-cast $\mathrm{Mg}$-Al-Ca base alloy. Scripta Materialia, 51(10), pp. 1005-1010, 2004.

[8] Luo A. A., Balogh M. P. \& Powell B. R., Creep and microstructure of magnesium-aluminum-calcium based alloys. Metallurgical and Materials Transactions A, 33A(3), pp. 567-574, 2002.

[9] Kim Y. K., Son H. T., Lee J. S., Oh I. H., Kim H. J. \& Bae J. C., Microstructure and mechanical properties of $\mathrm{Mg}$-Al-Ca alloys with yttrium addition. Key Engineering Materials, 345-346, pp. 73-76, 2007. 
[10] Zhong Y., Luo A., Sofo J. O. \& Liu Z., Laves phases in Mg-Al-Ca alloys. Magnesium Technology 2004, TMS Annual Meeting, pp. 317-323, 2004.

[11] Gertsman V. Y., Jian L., Su X., Thomson J. P. \& Mahi S., Microstructure and second-phase particles in low- and high-pressure die-cast magnesium alloy AM50. Metallurgical and Materials Transactions A, 36A(8), pp. 1989-1997, 2005.

[12] Lee S. G., Patel G. R. \& Gokhale A. M., Macro-segregation in highpressure die-cast AM60 alloy. Magnesium Technology 2005, TMS Annual Meeting, pp. 377-380, 2005.

[13] Yao J. \& Liu Z., Influence of AZ91 die-casting on its microstructure and mechanical properties. Rare Metals, 21(SUPPL.), pp. 69-74, 2002.

[14] Zhou M., Li N. \& Hu H., Effect of section thicknesses on tensile behavior and microstructure of high pressure die cast magnesium alloy AM50. Materials Science Forum, 475-479, pp. 463-468, 2005.

[15] Han L., Hu H., Northwood D. \& Li N., Microstructure and nano-scale mechanical behavior of $\mathrm{Mg}-\mathrm{Al}$ and $\mathrm{Mg}-\mathrm{Al}-\mathrm{Ca}$ alloys. Materials Science and Engineering A, 473(1-2), pp. 16-27, 2008.

[16] Han L., Hu H. \& Northwood D., Effect of Ca additions on microstructure and microhardness of an as-cast $\mathrm{Mg}-5.0 \mathrm{wt} \%$ Al alloy. Materials Letters, 62 (3), pp. 381-384, 2008.

[17] Han, L., Microstructure characterization and micro- and nano-scale mechanical behavior of $\mathrm{Mg}-\mathrm{Al}$ and $\mathrm{Mg}-\mathrm{Al}-\mathrm{Ca}$ alloys, $\mathrm{PhD}$ Thesis, University of Windsor, 2007.

[18] Huang Y. D., Hort N., Leil T. A., Kainer K. U. \& Y. L. Liu, Effect of microstructural inhomogeneity on creep response of $\mathrm{Mg}-\mathrm{Sn}$ alloys. Key Engineering Materials, 345-346, pp. 561-564, 2007. 